\title{
Scientific Collaboration across Time and Space: Bibliometric Analysis of the American Journal of Neuroradiology, 1980-2018
}

\author{
(D) V.M. Zohrabian, (D) L.H. Staib, (D) M. Castillo, and DL. Wang
}

\begin{abstract}
BACKGROUND AND PURPOSE: Scientific collaboration is traditionally acknowledged through coauthorship. Studies on this topic are few in the neuroimaging literature. This study is a bibliometric analysis of the American Journal of Neuroradiology (AJNR) between 1980 and 2018, with the primary aim of evaluating changes in article collaboration.
\end{abstract}

MATERIALS AND METHODS: Full bibliographic records from 1980 to 2018 were retrieved. Yearly metrics calculated included the number of articles published, the average number of authors, and the average number of affiliations per article. The levels of evidence of 160 random articles were determined. Geographic characteristics of author affiliations were analyzed. Changes across time were evaluated using linear regression, while Spearman rank-order correlation was used to determine relationships between level of evidence and time, number of authors, and number of affiliations.

RESULTS: There was a steady linear growth in the number of articles $\left(R^{2}=0.70, P<1 \mathrm{e}-10\right)$ from 1980 to 2018 . There were clear linear increases in the average number of authors $\left(R^{2}=0.91, P<\right.$ le-15) and affiliations $\left(R^{2}=0.90, P<\right.$ le-15) per article. There was a significant correlation between level of evidence and time period (Spearman $\rho=-0.42, P<1 \mathrm{e}-7$ ), indicating that articles trended toward better methodologic quality or strength of results over time. A significant correlation existed between the level of evidence and the number of authors (Spearman $\rho=-0.39, P<$ le-6). There were linear increases in the average number of different geographic locales of authors per article by country/region $\left(R^{2}=0.80, P<\right.$ le-13), state/province $\left(R^{2}=0.88, P<\right.$ le-15), and locality/city/town $\left(R^{2}=0.86, P<1 \mathrm{e}-15\right)$.

CONCLUSIONS: From 1980 to 2018, as the quantity of articles published in the AJNR increased, their level of evidence improved, while an increasing number of authors with different affiliations and from different geographic locales collaborated on these articles.

ABBREVIATION: WOS $=$ Web of Science

B ibliometric analyses continue to gain traction in the scientific literature as they use quantitative approaches to evaluate and compare research across countries, institutions, investigators, and journals. In more than a decade, only a very small number of studies in the American Journal of Neuroradiology (AJNR), the official journal of the American Society of Neuroradiology, have centered on bibliometrics. Whereas most of these have highlighted citation numbers or Impact Factors, ${ }^{1-5}$ few have underscored authorships or affiliations. ${ }^{6-9}$ Furthermore, even though a number of these inquiries have demonstrated continually increasing international contributions to the $A J N R,{ }^{7-9}$ none have

Received January 14, 2020; accepted after revision March 2.

From the Department of Radiology and Biomedical Imaging (V.M.Z., L.H.S.), Yale School of Medicine, New Haven, Connecticut; Department of Radiology (M.C.), University of North Carolina at Chapel Hill, Chapel Hill, North Carolina; and Cushing/Whitney Medical Library (L.W.), Yale University, New Haven, Connecticut.

Please address correspondence to Vahe M. Zohrabian, MD, Yale School of Medicine, PO Box 208042, New Haven, CT 06520-8042; e-mail: vahe.zohrabian@yale.edu

Indicates article with supplemental on-line photos.

http://dx.doi.org/10.3174/ajnr.A6523 focused on collaborations among researchers from different geographic areas. One prior study found high interdisciplinary cooperation in neurointerventional research published in the AJNR between 2003 and 2012, yet it did not examine other types of collaboration. ${ }^{10}$ Scientific collaboration, so valuable to the dissemination of knowledge and production of high-quality research, ${ }^{11}$ is traditionally acknowledged through coauthorship and, therefore, can be measured by the number of authors and affiliations. In this study, we hypothesized that collaborative efforts among researchers with different affiliations and from different geographic locales, both domestic and international, have grown with time. We conducted a systematic, in-depth analysis of the characteristics and trends of articles published in the AJNR between 1980 and 2018, with the primary aim of evaluating changes in collaboration during 4 decades.

\section{MATERIALS AND METHODS}

Institutional review board approval was not required because human subjects were not involved. The Web of Science (WOS) (Clarivate Analytics) was determined to be the optimal 
Table 1: Evidence-based medicine ratings, adapted from the AJNR Web site

\begin{tabular}{ll}
\hline Level & \multicolumn{1}{c}{ Study Type } \\
\hline 1 & Randomized controlled trial \\
2 & Prospective cohort study \\
3 & Retrospective cohort study, case-control study \\
4 & Case series \\
5 & Mechanism-based reasoning \\
\hline
\end{tabular}

bibliographic data source for this study. Full bibliographic records of all items $(n=14,758)$ published in the AJNR from January 1, 1980, to December 31, 2018, were retrieved from the WOS and saved as tab delimited data files. A custom script was written in Ruby, an open-source programming language, to extract a subset of the bibliographic records to include only those with a document type of "Article" $(n=10,789)$, defined in WOS as "reports of research on original works," which include "research papers, features, brief communications, case reports, technical notes, chronology, and full papers that were published in a journal and/or presented at a symposium or conference."12 This process excluded any comments, editorials, replies, letters, and reviews from our dataset. This subset of 10,789 bibliographic records served as the basis of all statistical analyses in this study.

The script also extracted all unique author affiliation addresses $(n=29,577)$ from the 10,789 bibliographic records and sent them individually to Google's Geocoding API, which returned standardized geographic locations of those addresses at the locality/city/town, state/province, and country/region levels. The geocoding results were checked for accuracy at the country/region level, and inaccuracies $(n=1293)$ were manually corrected.

The script grouped records by publication year and calculated the following metrics for each year: number of articles published, average number of authors per article, average number of affiliations per article, average number of affiliation countries/regions per article, average number of affiliation states/provinces per article, and average number of affiliation localities/cities/towns per article.

The script also generated a random sample of 20 records for each 5-year period between 1980 and 2014 and an additional 20 random records for the 4-year period between 2015 and 2018, totaling 160 records. Two trained individuals retrieved the full text of each of the articles and independently assigned a level of evidence (levels 1-5) to each according to the evidence-based medicine ratings guidelines published on the AJNR Web site, as in Table $1 .{ }^{13}$ After independent review, any disagreements were resolved by consensus.

The articles were also substratified by country/region of origin or the geographic affiliation of the primary author for the study. The countries/regions of origin were determined for most of the articles $(n=10,230,95 \%)$. The affiliation country/region of the last/senior author, when available, was established as the article origin. For the purposes of this study, we presumed that the last/ senior author's institution was the focal point of the work and where the work originated. For articles without such information, an origin was recognized if only a single affiliation country/region was listed for the article.
Visual representations of international collaboration across time were achieved by plotting network diagrams using Cytoscape (Cytoscape Consortium, Version 3.7.2, 2019; https://cytoscape.org/ download.html). The "nodes" in the diagrams represented countries/regions with articles that had at least 1 coauthor from a different country/region, and the size of the nodes represented the number of such articles. The nodes were linked by "edges," the thickness of which represented the number of articles with coauthors from the pair of connected countries/regions. The network diagrams were scaled using Cytoscape for better readability.

All data were tabulated and statistical analyses performed using R statistical and computing software (Version 3.3.2, 2016; http://www.r-project.org/). Changes with time were evaluated using linear regression. The Spearman rank-order correlation was used to assess relationships between level of evidence and time, number of authors, and number of affiliations.

\section{RESULTS}

\section{Number of Articles}

A total of 10,789 articles published in AJNR between 1980 and 2018 met the inclusion criteria for this bibliometric study. As shown in On-line Fig 1, there was a steady linear growth in the number of articles published yearly in the AJNR since $1980\left(R^{2}=\right.$ $0.70, P<1 \mathrm{e}-10$ ), from 85 articles in 1980 to 321 articles in 2018. Article counts increased, on average, by 6.4 each year.

\section{Number of Authors and Affiliations}

On-line Fig 2 shows linear increases in the average number of authors $\left(R^{2}=0.91, P<1 \mathrm{e}-15\right)$ and affiliations $\left(R^{2}=0.90\right.$, $P<1 \mathrm{e}-15)$ per article. The average number of authors per article increased by 0.10 per year. The average number of affiliations per article increased by 0.08 per year. The average number of authors per article was 3.4 in 1980, 5.3 in 2000, and 8.0 in 2016. The average number of affiliations represented in each article was 1.6 in 1980, 2.5 in 2000, and 4.4 in 2016.

\section{Level of Evidence}

There was a significant correlation between the level of evidence and time period (Spearman $\rho=-0.42, P<1 \mathrm{e}-7$ ), indicating that articles trended toward better methodologic quality or strength of results across time, as shown in On-line Fig 3. For example, the proportion of level 5 articles decreased, while level 3 and 4 articles increased during the 4 decades.

\section{Level of Evidence and Number of Authors and Affiliations}

A significant correlation was found between the level of evidence and the number of authors (Spearman $\rho=-0.39, P<1 \mathrm{e}-6$ ), as shown in On-line Fig 4. The proportion of level 5 articles decreased as the number of authors increased. However, no significant relationship was found between the level of evidence and the number of affiliations (Spearman $\rho=-0.15, P=.054$, not significant).

\section{Geographic Locales of Author Affiliations}

Authors from the United States were, by far, the largest contributors to AJNR, appearing in 6270 (58\%) articles. The United States 
Table 2: Number of articles with at least $N$ affiliation countries/regions

\begin{tabular}{lrrrcccccc}
\hline Time Span & $\boldsymbol{n}=\mathbf{2}$ & $\boldsymbol{n}=\mathbf{3}$ & $\boldsymbol{n}=\mathbf{4}$ & $\boldsymbol{n = 5}$ & $\boldsymbol{n}=\mathbf{6}$ & $\boldsymbol{n}=\mathbf{7}$ & $\boldsymbol{n}=\mathbf{8}$ & $\boldsymbol{n}=\mathbf{9}$ & $\boldsymbol{n}=\mathbf{1 0}$ \\
\hline All & 1456 & 250 & 74 & 36 & 21 & 8 & 4 & 2 & 2 \\
$1980-1989$ & 72 & 5 & 1 & 0 & 0 & 0 & 0 & 0 & 0 \\
$1990-1999$ & 183 & 12 & 1 & 0 & 0 & 0 & 0 & 0 & 0 \\
2000-2009 & 453 & 65 & 12 & 6 & 4 & 0 & 0 & 0 & 0 \\
2010-2018 & 748 & 168 & 60 & 30 & 17 & 8 & 4 & 2 & 2 \\
\hline
\end{tabular}

Table 3: Percentages of AJNR articles with all authors from the same geographic locales $^{\text {a }}$

\begin{tabular}{lccc}
\hline Time Span & Same Country/Region & Same State/Province & Same Locality/City/Town \\
\hline $1980-1989$ & $96 \%$ & $82 \%$ & $74 \%$ \\
$1990-1999$ & $93 \%$ & $72 \%$ & $65 \%$ \\
$2000-2009$ & $87 \%$ & $58 \%$ & $50 \%$ \\
$2010-2018$ & $75 \%$ & $43 \%$ & $37 \%$ \\
\hline
\end{tabular}

${ }^{a}$ Here, "All" refers to all authors in the author line of a single article being from the same geographic locale, either the same country/region, state/province, or locality/city/town.

Table 4: Percentage of international collaboration articles involving the United States

\begin{tabular}{lcccc}
\hline & $\begin{array}{c}\text { No. of } \\
\text { Collaborating } \\
\text { Countries/ } \\
\text { Regions }\end{array}$ & $\begin{array}{c}\text { No. of } \\
\text { International } \\
\text { Collaborating } \\
\text { Articles }\end{array}$ & $\begin{array}{c}\text { No. of International } \\
\text { Collaborating } \\
\text { Articles Involving } \\
\text { the United States }\end{array}$ & $\begin{array}{c}\text { \% of International } \\
\text { Collaborating } \\
\text { Articles Involving } \\
\text { the United States }\end{array}$ \\
\hline $1980-1989$ & 24 & 72 & 53 & $74 \%$ \\
$1990-1999$ & 32 & 183 & 125 & $68 \%$ \\
$2000-2009$ & 47 & 453 & 317 & $70 \%$ \\
$2010-2018$ & 57 & 748 & 465 & $62 \%$ \\
\hline
\end{tabular}

percentages of AJNR articles by authors from the same country/region, state/province, and locality/city/town decreased during the 4 time periods, with the largest decrease occurring at the locality/city/town level. For example, $74 \%$ of $A J N R$ articles were by authors from the same locality/city/ town during 1980-1989. That percentage dropped to $37 \%$ during $2010-$ 2018. At the state/province level, the percentage dropped from $82 \%$ to $43 \%$, while at the country/region level, it dropped from $96 \%$ to $75 \%$.

Nearly all countries/regions were increasingly involved in international collaborations across time. On-line Fig 7 reveals that on the basis of the change between the last 2 decades, China had the largest gain in international collaborations (606\%), followed by Norway (340\%), Spain (338\%), and France (319\%). The United States (147\%), Germany (145\%), and Japan (108\%), on the other hand, demonstrated more modest gains during the past 2 decades. Table 4 demonstrates

Table 5: Top 5 countries/regions collaborating internationally in AJNR, 1980-2018

\begin{tabular}{lc}
\multicolumn{1}{c}{ Country } & Article Count \\
\hline United States & 960 \\
Germany & 291 \\
Canada & 255 \\
France & 187 \\
United Kingdom & 171 \\
\hline
\end{tabular}

was followed by Japan (9\%), Germany (7\%), and Canada (5\%) as the next largest contributing countries.

As in On-line Fig 5, more than half $(n=5658,55 \%)$ of $A J N R$ articles published between 1980 and 2018 (whose origins could be determined) originated from the United States. The United States was followed by Japan (8\%), Germany (5\%), and Canada (4\%) as the next largest origin countries.

A detailed assessment of geographic locales of author affiliations in each article was performed. On-line Fig 6 demonstrates linear increases in the average number of different geographic locales of author affiliations per article from 1980 to 2018 by country/region $\left(R^{2}=0.80, P<1 \mathrm{e}-13\right)$, state/province $\left(R^{2}=0.88\right.$, $P<1 \mathrm{e}-15)$, and locality/city/town $\left(R^{2}=0.86, P<1 \mathrm{e}-15\right)$. The average number of countries/regions represented in each article increased by 0.01 per year. The average number of states/provinces per article increased by 0.03 per year. The average number of localities/cities/towns per article increased by 0.04 per year. Of the 10,789 articles analyzed, $1456(14 \%)$ were the result of collaborations between at least 2 countries/regions, and 250 (2\%), among at least 3 . These numbers trended upward across the decades, as shown in Table 2. Furthermore, as shown in Table 3, the that the United States held a decreasing share of the "international collaboration pie" across time because the percentage of such articles involving the United States decreased from 19801989 (74\%) to $2010-1018$ (62\%).

The complexity of the network diagrams increased during the 4 time periods, 1980-1989 (On-line Fig 8A), 1990-1999 (On-line Fig 8B), 2000-2009 (On-line Fig 8C), and 2010-2018 (On-line Fig $8 D$ ). Between 1980 and 1989, only 24 countries/regions (in 39 pairs) published articles in the AJNR with international coauthors. These numbers increased to 57 and 368, respectively, between 2010 and 2018. The top 5 countries/regions that collaborated internationally in the $A J N R$, and the top 3 collaboration pairs overall (1980-2018) are presented in Tables 5 and 6.

\section{DISCUSSION}

Collaboration enhances the quality of scientific research. Collaboration allows sharing of knowledge, facilitates acquisition of specialized and new expertise, fosters creativity, and promotes innovation. While macro-level collaborations are typically large inititatives by collaborating nations or international organizations, meso-level collaborations are usually among academic institutions, sometimes across national boundaries. ${ }^{14}$ Micro-level collaborations, on the other hand, involve individual researchers or small groups of individual researchers working together. ${ }^{14}$ The formal acknowledgment of scientific collaboration is traditionally through coauthorship and can be measured by the number of authors and affiliations. In this study, we performed in-depth bibliometric analyses of the characteristics and trends of AJNR articles published during the past 4 decades, from 1980 to 2018 . We 
Table 6: Top 3 pairs overall collaborating internationally in AJNR, 1980-2018

\begin{tabular}{lcc}
\hline Country 1 & Country 2 & Pair Count \\
\hline Germany & United States & 149 \\
Canada & United States & 147 \\
Japan & United States & 109 \\
\hline
\end{tabular}

examined article counts, level of evidence, number of authors, and the number and geography of author affiliations and, in doing so, proved that collaboration has increased across the years.

In examining collaborations, we established that the average number of authors per article increased by 0.10 per year, from 3.4 per article in 1980 to 8.0 per article in 2018. Multiple prior studies have likewise demonstrated a trend toward a greater number of authors per article, which may, in part, be due to increasing scientific complexity and specialization. ${ }^{15-17}$ Our manual analysis of a small random sample of 160 articles revealed that the level of evidence has improved since 1980, trending toward better methodologic quality or strength of results. Whereas studies published in 1980 were all level 4 or 5 , studies in 2015 were mostly level 2 or 3 . Furthermore, we demonstrated a significant association between the level of evidence and the number of authors so that more methodologically robust studies tended to have a larger number of authors and vice-versa. However, this finding is a correlation, and we have not proved that the number of authors and the level of evidence are causally related. A prior study showed that the number of authors per article was larger for original research than for case reports and review articles. ${ }^{18}$ On the other hand, increasing authorship may be merely because publications are an increasingly central part of recruitment, promotion, and retention of faculty in academic medicine. ${ }^{16,19-21}$ In fact, increasing coauthorship in the biomedical literature has been subject to debate, especially in the radiology literature, because several authors have noted increasing trends of inappropriate authorship during several decades. ${ }^{15,22-25}$

A recently published analysis of the impact of the recommendations of the International Committee of Medical Journal Editors on 49 clinical radiology journals between 1946 and 2013 found that overall authorship increased with time, independent of the journal of publication, country of publication, publication type, and language of publication. Moreover, of the top 10 radiology journals by volume, AJNR ranked above the average for change in authorship with time. ${ }^{18}$ Therefore, authors are reminded to strictly adhere to the guidelines of the International Committee of Medical Journal Editors, which are specified on the AJNR Web site, to ensure proper attribution of authorship.

In our examination, we also established that the average number of affiliations per article increased by 0.08 per year. However, no significant association was found between the level of evidence and the number of affiliations. We speculate that access to intrainstitutional diversity of expertise has improved with time and has helped in conducting studies that required more methodologic rigor.

Authors from the United States were, by far, the largest contributors to the AJNR, appearing in 6270 (58\%) articles. The United States was followed by Japan (9\%), Germany (7\%), and
Canada (5\%). During the 4 decades, however, the percentage of articles with authors from the United States declined (-30\%), from $80 \%$ in $1980-1989$ to $50 \%$ in $2010-2018$, while the percentages of articles with authors from other countries/regions increased, with China and Germany demonstrating the largest increases $(+7 \%)$. The United States was the origin country for more than half $(n=5658,55 \%)$ of all AJNR articles published between 1980 and 2018 whose origins could be determined, which is not surprising because AJNR is the official journal of the American Society of Neuroradiology. The United States was followed by Japan (8\%), Germany (5\%), and Canada (4\%) as the next largest origin countries. However, the percentage of articles originating from the United States declined $(-36 \%)$ with time, from $80 \%$ in $1980-1989$ to $44 \%$ in $2010-2018$, while South Korea $(+6 \%)$ and China (+5\%) demonstrated the largest gains.

Our data are consistent with a previously published work that has shown that although the United States is the largest contributor of articles to selected journals in clinical radiology between 1991 and 2000 (43.2\%), the relative shares of the United States, United Kingdom, and Canada have decreased, whereas those of Japan, France, Germany, Italy, South Korea, Spain, Switzerland, Turkey, Austria, and China have increased. ${ }^{26}$ Additionally, a study in the American Journal of Roentgoenology found that from 1980 to 1982, ten percent of the articles originated from institutions outside the United States, but between 1990 and 1992, international articles accounted for $25 \%$ of published articles. ${ }^{27} \mathrm{~A}$ follow-up of the study found that while the total number of published articles from most nations increased from 1980 to 2002, Korea, Japan, and Germany made the largest advances. ${ }^{28}$ Moreover, our study confirmed a prior work in the $A J N R$, which noted a relative decline in contributions from the United States since 1992 and proposed that articles from China, India, and Eastern Europe would continue to increase as the economies of these countries expanded and became more integrated with the rest of the world through globalization. ${ }^{9}$

Most interesting, beyond merely observing increasing international contributions in the $A J N R$, when the geography of coauthors' affiliations was examined, we confirmed a trend toward increasing national and international collaborations on articles during 4 decades. This is demonstrated by an increase in the average number of geographic locales per article by year in On-line Fig 6 and is visually portrayed by the increasing complexity and interconnectivity of the network diagrams in On-line Fig $8 A-D$. Internationally, the United States and Germany $(n=149)$, the United States and Canada $(n=147)$, and the United States and Japan $(n=109)$ collaborated on the greatest number of articles between 1980 and 2018, though nearly all countries/regions demonstrated increasing international collaboration. China demonstrated the largest gain, with a 606\% increase between 2000 and 2009 and 2010 and 2018, followed by Norway (340\%), Spain (338\%), and France (319\%). On the other hand, the United States demonstrated a more modest gain of $147 \%$ during these last 2 decades, followed by Germany (145\%) and Japan (108\%).

As the volume of international collaboration increased across time, the relative percentage of each country/region declined. For example, although the United States, both as an origin and collaborating country, contributed the largest number of AJNR articles during the 4 decades, its relative share in international collaboration 
decreased with time, as shown by the declining percentages of international collaboration articles involving the United States in Table 4. A trend of increasing collaboration across academic borders in science and engineering and the social sciences has been noted on a much larger scale by Jones et al. ${ }^{29}$ In examining 4.2 million research articles published between 1975 and 2005, the researchers demonstrated that multi-university collaborations grew from $10 \%$ of articles in 1975 to $30 \%-35 \%$ of articles in 2005, while single-author articles became increasingly rare during the same time period. ${ }^{29}$ However, the researchers also found that the average distance between collaborators grew only slightly, from 725-750 miles in 1975 to 800 miles in $2005 .^{29}$ This latter finding is also substantiated in our study because we found that the percentage of articles by authors from the same country/region decreased to a much lesser extent during the 4 decades than the percentages of those by authors from the same state/province, and especially the same locality/city/town, as shown in Table 3.

The digital age has lowered the transaction costs for international collaboration by breaking down barriers related to physical distance and variations in technology. ${ }^{30}$ Technologic advancements have made it much easier to communicate, and a multitude of Web sites and apps have enabled users to create and share content in the virtual space. Social media and social collaborative networks, which saw a revolution in the 21st century, have permeated nearly every aspect of personal and professional lives. The number of social media users worldwide has more than doubled in less than a decade, from 0.97 billion in 2010 to 2.62 billion in 2018. ${ }^{31}$ As artificial intelligence and machine learning continue to transform social media platforms, they will likely become even more pervasive. While earlier studies have shown a low frequency of social media use among scientists, ${ }^{32-34}$ the landscape is quickly changing, with a recent survey in Nature revealing that more than $95 \%$ of respondents have used some form of social media or social collaborative network for professional purposes, that $50 \%$ of professional users access Facebook on a daily basis, and that most respondents use social media for discovering and/or reading scientific content. ${ }^{35}$ Most interesting, in our study, we noted that the most rapid change in the average number of geographic locales per article took place since 2006, in the midst of the social media revolution, as shown in On-line Fig 6. However, this trend, albeit more modest, is also observed in the 1980 s to 1990 s, long before the Internet and social media boom, implying that additional factors are responsible for growth in collaboration.

There are several limitations to our study, most of which pertain to data extraction. At the time of this study, we were not able to dissect author affiliations down to institutional or departmental levels because such information in a structured, consistent format was not immediately available for retrieval. Instead, we had to rely on geographic location data parsed from author affiliation addresses by Google's Geocoding API. Although fairly accurate, we found that results returned from the API had some inaccuracies at the country/region level at a rate of $4.37 \%$ (1293 of 29,577), affecting $9.39 \%$ (1013 of 10,789) of all records. These inaccuracies were manually corrected, but only at the country/ region level. Due to resource constraints, it was not practical to check and correct for inaccuracies at the state/province and locality/city/town levels; therefore, geocoding inaccuracy rates at these levels are not known. However, on the basis of our cursory review of records and the low inaccuracy rate for country/region, these inaccuracies are likely minor.

Additionally, we realize that in some instances, authors may have recorded multiple affiliations. Unfortunately, data from WOS do not specify primary or secondary affiliations. In our study, authors and affiliations were analyzed separately most of the time. In those cases, all authors and affiliations were considered. The linkage between authors and affiliations was only relevant when determining country/region of origin for each article. In that case, we had to choose 1 (and only 1) affiliation for the last author and use the country/region for that affiliation as the country/region of origin for the article. For this specific analysis, affiliations were considered only at the country/region level, and very few articles $(n=26)$ had last/senior author affiliations spanning multiple countries/regions, representing only $0.25 \%$ of articles whose countries/regions of origin were determined $(n=10,230)$ and $0.24 \%$ of all articles in our dataset $(n=10,789)$. Given the very small number of such articles, any potential inaccuracies caused by multiple affiliations were likely minimal.

Furthermore, in assigning country of origin, we presumed that the last author's institution was the focal point of the work that was done and geographically where the work originated. In the radiology literature, the convention is that the first author is the greatest contributor to the work and is its principal writer, whereas the last author is the more senior and experienced one responsible for its content. Because scholarly output is an increasingly important part of promotion, younger researchers need to publish as first authors early in their academic careers when they may be still be in training, change specialties, or switch institutions or even countries altogether. Because senior authors tend to be higher on the academic ladder, their affiliations are less likely to change. However, this latter point is an inference based on anecdotal evidence and may not be entirely consistent. Moreover, the records we analyzed were of those published between 1980 and 2018. When we compared metrics by decades, the last decade (2010-2018) was 1 year shorter than the other decades. Consequently, when we generated a smaller sample for level-of-evidence grading by 5-year periods, the last period (2015-2018) was shorter by 1 year. However, because we were interested in examining larger trends across decades, inclusion of data from 1 additional year was not likely to considerably alter our findings.

Finally, our study uses the number of authors and the geography of affiliations as proxies for collaboration. As discussed earlier, inappropriate authorship is a problem facing not only radiology, but all of medicine. To what extent inappropriate authorship was represented in our bibliographic sample and how this may have influenced our findings are not known. Future studies might use sophisticated metrics for collaboration, such as a collaborative index, degree of collaboration, collaborative coefficient, modified collaborative coefficient, and degree of centrality, as well as examine relationships of these metrics with research productivity, journal Impact Factor, and number of citations. Larger analyses might also be stratified by article topic or category, for example, brain, spine, head and 
neck, and interventional procedures, to ascertain differences in levels of evidence as well as to quantify levels of evidence for countries of origin and correlate these findings with changes in the number of articles from these countries across time.

\section{CONCLUSIONS}

Scientific collaboration is essential for the dissemination of knowledge and production of high-quality research. From 1980 to 2018, as the quantity of articles published in the AJNR increased, their level of evidence improved, while an increasing number of authors with different affiliations and from different geographic locales collaborated on these articles.

\section{REFERENCES}

1. Castillo M. Citations and open access: questionable benefits. AJNR Am J Neuroradiol 2009;30:215-16 CrossRef Medline

2. Castillo M. Measuring academic output: the $\mathbf{H}$-index. AJNR Am J Neuroradiol 2010;31:783-84 CrossRef Medline

3. Choudhri AF, Castillo M. Subspecialty virtual Impact Factors within a dedicated neuroimaging journal. AJNR Am J Neuroradiol 2015;36:1810-13 CrossRef Medline

4. McDonald RJ, Cloft HJ, Kallmes DF. Fate of submitted manuscripts rejected from the American Journal of Neuroradiology: outcomes and commentary. AJNR Am J Neuroradiol 2007;28:1430-34 CrossRef Medline

5. McDonald RJ, Cloft HJ, Kallmes DF. Fate of manuscripts previously rejected by the American Journal of Neuroradiology: a follow-up analysis. AJNR Am J Neuroradiol 2009;30:253-56 CrossRef Medline

6. Huntley JH, Pakpoor J, Yousem DM. The top 20 most prolific authors in the American Journal of Neuroradiology: what is their impact? AJNR Am J Neuroradiol 2018;39:2182-86 CrossRef Medline

7. Emamzadehfard S, Eslami V, Yousem DM, et al. Disproportionate international contributions to subspecialties of neuroradiology in the American Journal of Neuroradiology. AJNR Am J Neuroradiol 2019;40:E3-E4 CrossRef Medline

8. Charkhchi P, Mirbolouk M, Jalilian R, et al. Who's contributing most to American neuroscience journals: American or foreign authors? AJNR Am J Neuroradiol 2018;39:1001-07 CrossRef Medline

9. Cloft HJ, Cloft KJ. How American is the American Journal of Neuroradiology? AJNR Am J Neuroradiol 2007;28:601 Medline

10. Lee JY, Yoon DY, Yoon SD, et al. Neurointerventional research between 2003 and 2012: slow growth, high interdisciplinary collaboration, and a low level of funding. AJNR Am J Neuroradiol 2014;35:1877-82 CrossRef Medline

11. Freeman RB, Huang W. Collaboration: strength in diversity. Nature 2014;513:305 CrossRef Medline

12. Searching the Document Type Field: Web of Science Core Collection Help. Clarivate Analytics; 2018. https://images.webofknowledge.com/ images/help/WOS/hs_document_type.html. Accessed October 10, 2019

13. Evidence-Based Medicine Ratings. American J of Neuroradiology; 2019. http://www.ajnr.org/page/content/EBM

14. Abbasi A, Hossain L, Uddin S, et al. Evolutionary dynamics of scientific collaboration networks: multi-levels and cross-time analysis. Scientometrics 2011;89:687-710 CrossRef
15. Chew FS. Coauthorship in radiology journals. AJR Am J Roentgenol 1988;150:23-26 CrossRef Medline

16. Weeks WB, Wallace AE, Kimberly BC. Changes in authorship patterns in prestigious US medical journals. Soc Sci Med 2004;59:194954 CrossRef Medline

17. Gaeta TJ. Authorship: "law" and order. Acad Emerg Med 1999;6:297301 CrossRef Medline

18. Dang W, McInnes MD, Kielar AZ, et al. A comprehensive analysis of authorship in radiology journals. PLoS One 2015;10:e139005 CrossRef Medline

19. Drenth JP. Multiple authorship: the contribution of senior authors. JAMA 1998;280:219-21 CrossRef Medline

20. Levsky ME, Rosin A, Coon TP, et al. A descriptive analysis of authorship within medical journals, 1995-2005. South Med J 2007;100:37175 CrossRef Medline

21. Baerlocher MO, Gautam T, Newton M, et al. Changing author counts in five major general medicine journals: effect of author contribution forms. J Clin Epidemiol 2009;62:875-77 CrossRef Medline

22. Chew FS. The scientific literature in diagnostic radiology for American readers: a survey and analysis of journals, papers, and authors. AJR Am J Roentgenol 1986;147:1055-61 CrossRef Medline

23. Mussurakis $S$. Coauthorship trends in the leading radiological journals. Acta Radiology 1993;34:316-20 Medline

24. Baek S, Yoon DY, Cho YK, et al. Trend toward an increase in authorship for leading radiology journals. AJR Am J Roentgenol 2015;205:924-28 CrossRef Medline

25. Chow DS, Ha R, Filippi CG. Increased rates of authorship in radiology publications: a bibliometric analysis of 142,576 articles published worldwide by radiologists between 1991 and 2012. AJR Am J Roentgenol 2015;204:W52-57 CrossRef Medline

26. Rahman M, Haque TL, Fukui T. Research articles published in clinical radiology journals: trend of contribution from different countries. Acad Radiology 2005;12:825-29 CrossRef Medline

27. Elster AD, Chen MY. The internationalization of the American Journal of Roentgenology: 1980-1992. AJR Am J Roentgenol 1994;162:519-22 CrossRef Medline

28. Chen MY, Jenkins CB, Elster AD. Internationalization of the American Journal of Roentgenology: 1980-2002. AJR Am J Roentgenol 2003;181:907-12 CrossRef Medline

29. Jones BF, Wuchty S, Uzzi B. Multi-university research teams: shifting impact, geography, and stratification in science. Science 2008;322:125962 CrossRef Medline

30. Sun H, Puterbaugh MD. Using social media to promote international collaboration. Pennsylvania Libraries: Research \& Practice 2013;1:60-74 CrossRef

31. J. Clement. Number of social network users worldwide from 2010 to 2021. August 14, 2019. https://www.statista.com/statistics/278414/numberof-worldwide-social-network-users/. Accessed January 10, 2020

32. Priem J, Costello K, Dzuba T. Prevalence and use of Twitter among scholars. January 15, 2015. https://s3-eu-west-1.amazonaws.com/ pfigshare-u-files/232738/5uniposter.png. Accessed January 10, 2020

33. Wilkinson C, Weitkamp E. A case study in serendipity: environmental researchers use of traditional and social media for dissemination. PLoS One 2013;8:e84339 CrossRef Medline

34. Collins K, Shiffman D, Rock J. How are scientists using social media in the workplace? PLoS One 2016;11:e0162680 CrossRef Medline

35. Nature Research. Springer Nature 2017_Social Media Survey. 2017 